\title{
Two Iterative Methods to Solve Nonlinear Equations of Load Flows
}

\author{
Rubén Villafuerte D., Jesús Medina C., Rubén A. Villafuerte S., Victorino Juárez R.
}

\begin{abstract}
This paper presents the results obtained when two iterative methods are applied to the solution of non-linear equations that model the load flow in electric power systems. Two iterative methods are applied; the first consists of a simplification of the rectangular form the traditional Newton-Raphson method, the second is a hybrid method and relates the simplified form proposed here and a four-step Newton-type iterative method. The convergence characteristic and the mathematical preliminaries of the iterative four-step method are included in the paper. The methods were used to calculate the voltages at each node of the IEEE test system of 118 nodes and a distribution system of 40 nodes. In each method, the formation of the Jacobian matrix, widely used in traditional forms of load flows, is avoided and only elementary operations are carried out, impacting the execution times for the test systems used, being of the order of 15.6 to 279 milliseconds. The maximum error found is for the 118 node system and is of the order of $3.7 \%$.
\end{abstract}

Keywords: Iterative methods; load flows; nonlinear equations; power systems; Newton-Raphson.

\section{INTRODUCTION}

Power flow calculations evolved from the planning departments of electric utilities in the early 20th century, where they were (and still are) used to simulate the effects of network augmentations, different load scenarios, network configurations, etc. Early power flows were solved by AC network analyzers, which were analog computers containing resistors, inductors, and capacitors calibrated to be a miniature scale equivalent of the actual electrical network. For large systems, these network analyzers took up the space of entire rooms. As they were physical in nature, the network analyzers needed to be re-wired for each different configuration, augmentation or scenario to be studied. Starting with the paper by Ward and Hale in 1956, the use of digital computers would enable power flow calculations to be performed faster and in a more flexible manner [1]. The iterative method proposed by Ward and Hale (which became known as the Gauss-Seidel method) was straightforward to implement but exhibited poor convergence characteristics

Revised Manuscript Received on December 30, 2019.

* Correspondence Author

Rubén Villafuerte D*, Universidad Veracruzana, Facultad de Ingeniería, Ixtaczoquitlán Ver., México, rubenv46@yahoo.com.mx, rvillafuerte@uv.mx.

Jesús Medina C., Universidad Veracruzana, Facultad de Ingeniería, Ixtaczoquitlán Ver., México, jemedina@uv.mx

Rubén A., Villafuerte S. Instituto Tecnológico Nacional, Campus Orizaba, Orizaba, Ver., México, dreyko999@gmail.com

Victorino Juárez R., Universidad Veracruzana, Facultad de Ingeniería, Ixtaczoquitlán Ver., México, vijuarez@uv.mx

(C) The Authors. Published by Blue Eyes Intelligence Engineering and Sciences Publication (BEIESP). This is an open access article under the CC BY-NC-ND license (http://creativecommons.org/licenses/by-nc-nd/4.0/)
In 1961, Van Ness and Griffin introduced Newton's method for solving power flows (which later became known as the Newton-Raphson method), which had more favorable characteristics but was limited to smaller networks due to computer memory requirements [2].

In their 1967 paper, Tinney and Hart exploited the sparsity properties of the Ybus matrix (and by extension, the Jacobian matrix) and in conjunction with numerical techniques such as triangular factorization and optimal ordering, were able to make the Newton-Raphson algorithm practical for solving large networks using the computing resources available at the time [3]. In 1974, Stott and Alsac, recognized that in many practical networks there was decoupling between 1) active power and voltage and 2) reactive power and phase angle [4]. The proposed an algorithm (the fast decoupled load flow) that significantly reduced the computational requirements to construct the Jacobian matrix and therefore led to large gains in computational speed (although at the expense of a little accuracy). In paper [5] gives an overview of the various load flow techniques of the weakly meshed distribution system which are very efficient, because various classical methods are not having sufficient convergence criterion for solving the large distribution system. In paper [6] a simple and powerful algorithm has been proposed for balanced radial distribution network to obtain power flow solution. It has been found from the cases presented that the proposed method has fast convergence characteristics when compared to existing methods. The algorithm is found to be robust in nature. The method can be easily extended to solve three phase networks also. In paper [7] a procedure is established for solving the Probabilistic Load Flow in an electrical power network, considering correlation between power generated by power plants, loads demanded on each bus and power injected by wind farms. The method proposed is based on the generation of correlated series of power values, which can be used in a Monte Carlo simulation, to obtain the probability density function of the power through branches of an electrical network. In paper [8] a method is proposed to improve solutions for intervals of power flow problems due to nondeterministic characteristics of demand loads and output of generators. In paper [9] a detailed study for load flow analysis in distributed power system. A case study of modeling and simulation of the distribution network is implemented with the electrical transient analyzer program [10].

\section{Published By:}

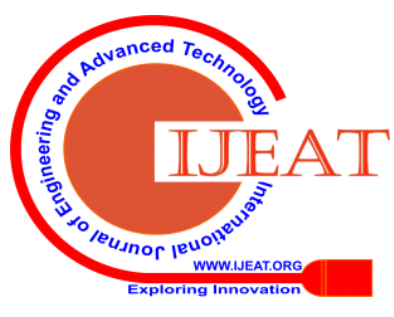




\section{PROPOSED METHODS AND CONVERGENCE ANALYSIS}

The objective of this work is to calculate the Voltage in each node of an electrical power system. To achieve this, the nonlinear equations that model the load flow are established and solved by applying a simplification of the Jacobian matrix used in the rectangular shape of the Newton-Raphson method [11]. Equation (1) models the load nodes of a system.

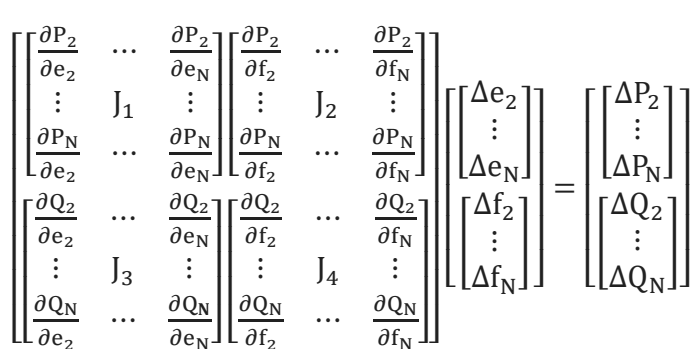

$\mathrm{i}=1, \mathrm{~N}, \mathrm{i} \neq$ Slack

The simplified form is generated for the diagonal elements of the submatrices of eq. (1). To calculate the rectangular components of the Voltages a system of two equations (2) is generated.

$\left[\begin{array}{l}{\left[\frac{\partial \mathrm{P}_{\mathrm{i}}}{\partial \mathrm{e}_{\mathrm{i}}}\right]\left[\begin{array}{c}\frac{\partial \mathrm{P}_{\mathrm{i}}}{\partial \mathrm{f}_{\mathrm{i}}}\end{array}\right]} \\ {\left[\frac{\partial \mathrm{Q}_{\mathrm{i}}}{\partial \mathrm{e}_{\mathrm{i}}}\right]\left[\begin{array}{c}\frac{\partial \mathrm{Q}_{\mathrm{i}}}{\partial \mathrm{f}_{\mathrm{i}}}\end{array}\right]}\end{array}\right]\left[\begin{array}{c}\Delta \mathrm{e}_{\mathrm{i}} \\ \Delta \mathrm{f}_{\mathrm{i}}\end{array}\right]=\left[\begin{array}{c}\Delta \mathrm{P}_{\mathrm{i}} \\ \Delta \mathrm{Q}_{\mathrm{i}}\end{array}\right] \mathrm{i}=1, \mathrm{~N}, \mathrm{i} \neq$ Slack

The elements of the submatrix $J_{i j}$ of (1) are generated in each iteration and depend on the partial derivatives of the real power or reactive power with respect to the nodal Voltages. The real and reactive power in each node is calculated with (3) and (4), respectively [11, 12, 17].

$P_{i}=e_{i} \sum_{j=1,}^{N}\left(G_{i j} e_{j}-B_{i j} f_{j}\right)+f_{i} \sum_{i=j,}^{N}\left(G_{i j} f_{j}+B_{i j} e_{j}\right), i=$

$1, \mathrm{~N}, \mathrm{i} \neq$ Slack

$\mathrm{Q}_{\mathrm{i}}=\mathrm{f}_{\mathrm{i}} \sum_{\mathrm{j}=1,}^{\mathrm{N}}\left(\mathrm{G}_{\mathrm{ij}} \mathrm{e}_{\mathrm{j}}-\mathrm{B}_{\mathrm{ij}} \mathrm{f}_{\mathrm{j}}\right)-\mathrm{e}_{\mathrm{i}} \sum_{\mathrm{i}=\mathrm{j},}^{\mathrm{N}}\left(\mathrm{G}_{\mathrm{ij}} \mathrm{f}_{\mathrm{j}}+\mathrm{B}_{\mathrm{ij}} \mathrm{e}_{\mathrm{j}}\right), \mathrm{i}=$

$1, N, i \neq$ Slack

The partial derivatives of the real and reactive power with respect to the rectangular components are expressed by (5)(8).

$\frac{\partial P_{i}}{\partial e_{i}}=2 G_{i i} e_{i}+\sum_{j=1, i \neq j}^{N}\left(G_{i j} e_{j}-B_{i j} f_{j}\right)$

$\frac{\partial P_{i}}{\partial f_{i}}=2 G_{i i} f_{i}+\sum_{j=1, i \neq j}^{N}\left(G_{i j} f_{j}+B_{i j} e_{j}\right)$

$\frac{\partial Q_{i}}{\partial e_{i}}=-2 B_{i i} e_{i}-\sum_{j=1, i \neq j}^{N}\left(G_{i j} f_{j}+B_{i j} e_{j}\right)$

$\frac{\partial Q_{\mathrm{i}}}{\partial \mathrm{f}_{\mathrm{i}}}=-2 B_{\mathrm{ii}} \mathrm{f}_{\mathrm{i}}+\sum_{\mathrm{j}=1, \mathrm{i} \neq \mathrm{j}}^{\mathrm{N}}\left(\mathrm{G}_{\mathrm{ij}} e_{j}-\mathrm{B}_{\mathrm{ij}} \mathrm{f}_{\mathrm{j}}\right)$

The increases in real and reactive power are calculated in each iteration with (9)-(10).

$\Delta P_{i}=P_{i \text { spec }}-P_{i \text { calc }} \quad \mathrm{i} \neq$ Slack

$\Delta Q_{i}=Q_{\text {ispec }}-Q_{i \text { calc }} \quad \mathrm{i} \neq$ Slack

Where:

$\mathrm{P}_{\mathrm{i} \text { spec }}$ Real power load in node $i$,

$\mathrm{Q}_{\mathrm{i} \text { spec }}$ Reactive power load in node $i$,
$\mathrm{P}_{\mathrm{i} \text { calc }}$ Real power calculated at node $\mathrm{i}$,

$\mathrm{Q}_{\mathrm{i} \text { calc }}$ Reactive power calculated at node $\mathrm{i}$

For the solution of real nonlinear equations, methods of several steps and of high order of convergence have been proposed [13-17]. The method used in this work is four steps and only the function $f\left(x_{n}\right)$ and its derivative $f^{\prime}\left(x_{n}\right)$ are necessary.

\section{A. Convergence analysis for the four-step method}

In this section, the iterative method of four steps and fifth order of convergence is constructed, for which the following basic definitions are necessary:

Definition A.1. Let $\mathrm{f} \in \mathbf{C}^{\mathrm{m}}$ (D) be a function defined on an open interval $\mathrm{D}$, and let $\alpha$ there be a simple zero of the nonlinear equation $f(x)=0$ and $f^{\prime}(\alpha) \neq 0$. An iterative method is said to have an integer order of convergence $m$ if it produces the sequence $\left\{x_{n}\right\}$ of numbers such that:

or equivalently

$$
\lim _{n \rightarrow \infty} \frac{x_{n+1}-\alpha}{x_{n}-\alpha}=A \neq 0
$$

$$
x_{n}-\alpha=\mathrm{A}\left(\mathrm{x}_{\mathrm{n}}-\alpha\right)^{\mathrm{m}}+\mathrm{O}\left(\left(\mathrm{x}_{\mathrm{n}}-\alpha\right)^{\mathrm{m}+1}\right)
$$

Definition A.2. The efficiency of a method is measured by the index $E I=\rho^{1 / \beta}$, where $\rho$ is the order of the iterative method and $\beta$ is the total number of function evaluations per iteration.

Now, we consider the iteration scheme:

$\mathrm{y}_{\mathrm{n}}=x_{n}-\left(\frac{f\left(x_{n}\right)}{f^{\prime}\left(x_{n}\right)}\right) \alpha_{1}$

$z_{n}=y_{n}-\left(\frac{f\left(y_{n}\right)}{f^{\prime}\left(x_{n}\right)}\right) \alpha_{2}$

$u_{n}=z_{n}-\left(\frac{f\left(z_{n}\right)}{f^{\prime}\left(x_{n}\right)}\right) \alpha_{3}$

$x_{n+1}=u_{n}-\left(\frac{f\left(u_{n}\right)}{f^{\prime}\left(x_{n}\right)}\right) \alpha_{4}$

Where: $\alpha_{1}, \alpha_{2}, \alpha_{3}$ and $\alpha_{4}$ are real constants

Theorem A.1. Let $\alpha$ be a simple zero of sufficiently differentiable function $f: I \subseteq C \rightarrow C$ for an open interval I. If $x_{o}$ is sufficiently close to $\alpha$, the method defined by eq. (11)(14) has local order of convergence at least 5, with the following error equation

$e_{n+1}=-e_{k}^{5}\left(38 C_{2}^{4}+4 C_{2}^{2} C_{3}-7 C_{2} C_{4}-2 C_{3}^{2}+4 C_{5}\right)+$ $C_{2} e_{k}^{6}\left(118 C_{2}^{4}-125 C_{2}^{2} C_{3}+4 C_{2} C_{4}+32 C_{3}^{2}-2 C_{5}\right)+O\left(e_{k}^{7}\right)$

Where: $C_{k}=\frac{f^{k}(\alpha)}{k ! f^{\prime}(\alpha)} ; k=1,2,3$.. and the error function is expressed as: $\mathrm{e}_{\mathrm{n}}=\mathrm{x}_{\mathrm{n}}-\alpha$

Proof. Let $\alpha$ be a simple zero of $f(x)$. Then by using Taylor series with Derive, we have.

In the convergence test of an iterative method, each of the equations is developed in Taylor series. Thus, by developing a Taylor's series the function $f\left(x_{n}\right)$, we have eq. (15). 
$\mathrm{f}\left(\mathrm{x}_{\mathrm{n}}\right)=\mathrm{f}^{\prime}(\alpha)\left(\mathrm{e}_{\mathrm{n}}+\mathrm{C}_{2} \mathrm{e}_{\mathrm{n}}^{2}+\mathrm{C}_{3} \mathrm{e}_{\mathrm{n}}^{3}+\mathrm{C}_{4} \mathrm{e}_{\mathrm{n}}^{4}+\mathrm{C}_{5} \mathrm{e}_{\mathrm{n}}^{5}+\mathrm{C}_{6} \mathrm{e}_{\mathrm{n}}^{6}+\right.$ $(0) e_{n}^{7}$

Deriving successively $f\left(x_{n}\right)$, we obtain (16)-(20).

$$
f\left(x_{k}\right)=f^{\prime}(\alpha)\left(e_{k}+C_{2} e_{k}^{2}+C_{3} e_{k}^{3}+C_{4} e_{k}^{4}+C_{5} e_{k}^{5}+O\left(e_{k}^{6}\right)\right)
$$

$f^{\prime}\left(x_{k}\right)=f^{\prime}(\alpha)\left(1+2 C_{2} e_{k}+3 C_{3} e_{k}^{2}+4 C_{4} e_{k}^{3}+5 C_{5} e_{k}^{4}+\right.$ $\left.O\left(e_{k}^{5}\right)\right)$

$f^{\prime \prime}\left(x_{k}\right)=f^{\prime}(\alpha)\left(2 C_{2}+6 C_{3} e_{k}+12 C_{4} e_{k}^{2}+20 C_{5} e_{k}^{3}+\right.$ $\left.O\left(e_{k}^{4}\right)\right)$

$f^{(3)}\left(x_{k}\right)=f^{\prime}(\alpha)\left(6 C_{3}+24 C_{4} e_{k}+60 C_{5} e_{k}^{2}+O\left(e_{k}^{3}\right)\right)$

$f^{(4)}\left(x_{k}\right)=f^{\prime}(\alpha)\left(24 C_{4}+120 C_{5} e_{k}+O\left(e_{k}^{2}\right)\right)$

Where:

$C_{j}=\frac{f^{(j)}\left(x^{*}\right)}{J ! f^{\prime}\left(x^{*}\right)}, \mathrm{j}=2,3 \ldots, \mathrm{y} \mathrm{e}_{\mathrm{k}}=\mathrm{x}_{\mathrm{k}}-\mathrm{X}^{*}$

From (16)-(17), we have:

$\delta_{k}=-\frac{f\left(x_{k}\right)}{f^{\prime}\left(x_{k}\right)}=-e_{k}+C_{2} e_{k}^{2}+2 e_{k}^{3}\left(C_{3}-C_{2}^{2}\right)+$

$e_{k}^{4}\left(-7 C_{2} C_{3}+4 C_{2}^{3}+3 C_{4}\right)-2 e_{k}^{5}\left(4 C_{2}^{4}-10 C_{2}^{2} C_{3}+\right.$

$\left.5 C_{2} C_{4}+3 C_{3}^{2}-2 C_{5}\right)+O\left(e_{k}^{6}\right)$

From (16), (17) and (11), we have:

$y_{k}=C_{2} e_{k}^{2}+2 e_{k}^{3}\left(C_{3}-C_{2}^{2}\right)+e_{k}^{4}\left(-7 C_{2} C_{3}+4 C_{2}^{3}+3 C_{4}\right)-$ $2 e_{k}^{5}\left(4 C_{2}^{4}-10 C_{2}^{2} C_{3}+5 C_{2} C_{4}+3 C_{3}^{2}-2 C_{5}\right)+O\left(e_{k}^{6}\right)$

Expanding $f(y k)$ in the neighborhood of $x k$, we have:

$f\left(y_{k}\right)=f\left(x_{k}-\frac{f\left(x_{k}\right)}{f^{\prime}\left(x_{k}\right)}\right)=f\left(x_{k}\right)+f^{\prime}\left(x_{k}\right) \delta_{k}+$
$\frac{1}{2} f^{\prime \prime}\left(x_{k}\right) \delta_{k}^{2}+\frac{1}{3 !} f^{(3)}\left(x_{k}\right) \delta_{k}^{3}+\frac{1}{4 !} f^{(4)}\left(x_{k}\right) \delta_{k}^{4}+O\left(e_{k}^{5}\right)$

$f\left(y_{k}\right)=C_{2} e_{k}^{2}+2 e_{k}^{3}\left(C_{3}-C_{2}^{2}\right)+e_{k}^{4}\left(-7 C_{2} C_{3}+5 C_{2}^{3}+\right.$ $\left.3 C_{4}\right)-e_{k}^{5}\left(12 C_{2}^{4}-24 C_{2}^{2} C_{3}+10 C_{2} C_{4}+6 C_{3}^{2}-2 C_{5}\right)+$ $O\left(e_{k}^{6}\right)$

From the equation:

$z_{k}=y_{k}-\alpha_{2} \frac{f\left(y_{k}\right)}{f^{\prime}\left(x_{k}\right)}$

Considering that $\alpha_{2}$ is equal to one and relating (16), (23) and (12), we have that $z_{k}$ is equal to:

$z_{k}=2 C_{2}^{2} e_{k}^{3}+e_{k}^{4}\left(7 C_{3}-9 C_{2}^{2}\right)+e_{k}^{5}\left(30 C_{2}^{4}-44 C_{2}^{2}+\right.$

$\left.10 C_{2} C_{4}+6 C_{3}^{2}-C_{5}\right)+O\left(e_{k}^{6}\right)$

Applying the same procedure as (24), we have:

$f\left(z_{k}\right)=2 C_{2}^{2} e_{k}^{3}+C_{2} e_{k}^{4}\left(7 C_{3}-9 C_{2}^{2}\right)+e_{k}^{5}\left(19 C_{2}^{4}-30 C_{2}^{2}+\right.$ $\left.8 C_{2} C_{4}-6 C_{3}^{2}-2 C_{5}\right)+O\left(e_{k}^{6}\right)$

With (16), (24) and substituted in (13), we have: $u_{k}=14 e_{k}^{4}\left(C_{3}-C_{2}^{2}\right)+e_{k}^{5}\left(20 C_{2}^{4}-22 C_{2}^{2} C_{3}+2 C_{2} C_{4}-\right.$

$\left.6 C_{3}^{2}+C_{5}\right)+O\left(e_{k}^{6}\right)$

Evaluating the function $f\left(u_{k}\right)$ as in the equation (23), we have:

$f\left(u_{k}\right)=14 e_{k}^{4}\left(C_{3}-C_{2}^{2}\right)+e_{k}^{5}\left(30 C_{2}^{4}+10 C_{2}^{2} C_{3}-5 C_{2} C_{4}+\right.$ $\left.3 C_{3}^{2}+5 C_{5}\right)+C_{2} e_{k}^{6}\left(18 C_{2}^{4}+18 C_{2}^{2} C_{3}+10 C_{2} C_{4}-3 C_{3}^{2}+\right.$ $\left.8 C_{5}\right)+O\left(e_{k}^{7}\right)$

With (16), (28) and (14), considering that $\alpha_{4}$ is equal to one, we have:

$x_{k+1}=u_{k}-\frac{f\left(u_{k}\right)}{f^{\prime}\left(x_{k}\right)}=-e_{k}^{5}\left(38 C_{2}^{4}+4 C_{2}^{2} C_{3}-7 C_{2} C_{4}-\right.$

$\left.2 C_{3}^{2}+4 C_{5}\right)+C_{2} e_{k}^{6}\left(118 C_{2}^{4}-125 C_{2}^{2} C_{3}+4 C_{2} C_{4}+32 C_{3}^{2}-\right.$

$\left.2 C_{5}\right)+O\left(e_{k}^{7}\right)$

Equation (29) shows that the four-step method has a fifth order of convergence

The functions $f\left(x_{i}\right)$ with their derivatives of the four-step method modeled by (11)-(14), apply to the complex power equations in each node of an electric power system.

For node $i$, of a power system of $N$, nodes, we have (30).

$f_{i}\left(V_{1}, V_{2},, V_{N}\right)=S_{i}^{*}-V_{i}^{*}\left[\sum_{j=1}^{N} Y_{i j} V_{j}\right] \mathrm{i}=1, \mathrm{~N}-1$,

$i \neq$ Slack

Where:

$N$ Number nodes,

$S_{i j}$ Net complex power demanded in each node

$Y_{i j}$ Admittance between node $i$ and node $j$,

$V_{i}$ Voltage node $i$,

Also: $\mathrm{Y}_{\mathrm{ij}}, \mathrm{V}_{\mathrm{i}}, \mathrm{V}_{\mathrm{j}}, \mathrm{S}_{\mathrm{ij}}$ and $f_{\mathrm{i}}\left(V_{1}, V_{2}, \ldots V_{N}\right)$ are complex quantities and * it means conjugate of

Equation (30) is applied to the four-step method and (31)(34) are established for each node:

Step 1:

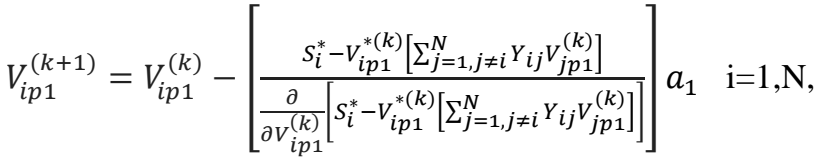

Slack node

Step 2:

$V_{i p 2}^{(k+1)}=V_{i p 1}^{(k+1)}-\left[\frac{s_{i}^{*}-V_{i p 1}^{*(k+1)}\left[\sum_{j=1, j \neq i}^{N} Y_{i j} V_{j p 1}^{(k+1)}\right]}{\left.\frac{\partial}{\partial V_{i p 1}^{(k)}\left[S_{i}^{*}-V_{i p 1}^{*(k)}\left[\sum_{j=1, j \neq i}^{N} Y_{i j} V_{j p 1}^{(k)}\right]\right]}\right]}\right] a_{2} \mathrm{i}=1, \mathrm{~N}, \mathrm{i}$

\# Slack node

Step 3:

Published By: 
$V_{i p 3}^{(k+1)}=V_{i p 2}^{(k+1)}-\left[\frac{s_{i}^{*}-V_{i p 2}^{*(k+1)}\left[\sum_{j=1, j \neq i}^{N} Y_{i j} V_{j p 2}^{(k+1)}\right]}{\frac{\partial}{\partial V_{i p 1}^{(k)}[}\left[S_{i}^{*}-V_{i p 1}^{*(k)}\left[\sum_{j=1, j \neq i}^{N} Y_{i j} V_{j p 1}^{(k)}\right]\right]}\right] a_{3} \quad \mathrm{i}=1, \mathrm{~N}$,

$\mathrm{i} \neq$ Slack node

Step 4:

$V_{i p 4}^{(k+1)}=V_{i p 3}^{(k+1)}-\left[\frac{s_{i}^{*}-V_{i p 3}^{*(k+1)}\left[\sum_{j=1, j \neq i}^{N} Y_{i j} V_{j p 3}^{(k+1)}\right]}{\frac{\partial}{\partial V_{i p 1}^{(k)}}\left[S_{i}^{*}-V_{i p 1}^{*(k)}\left[\sum_{j=1, j \neq i}^{N} Y_{i j} V_{j p 1}^{(k)}\right]\right]}\right] a_{4} \quad \mathrm{i}=1, \mathrm{~N}$,

$i \neq$ Slack node

\section{RESULTS AND DISCUSSION}

FORTRAN programs were developed to solve the nonlinear equations of the Voltage in each node of an electrical power system and apply to two test systems. That is, for the equation (2) the M1 program is developed and its results are compared with the test systems of 118 nodes of the IEEE and a distribution system of 40 nodes $[18,19]$. In all the simulations it is considered that the system operates in balanced conditions. In fig. 1, a flowchart shows the solution process of the proposed simplification and in fig. 2, the flowchart of the M2 program is shown, which considers the solution of (2) and the solution of (31)-(34).

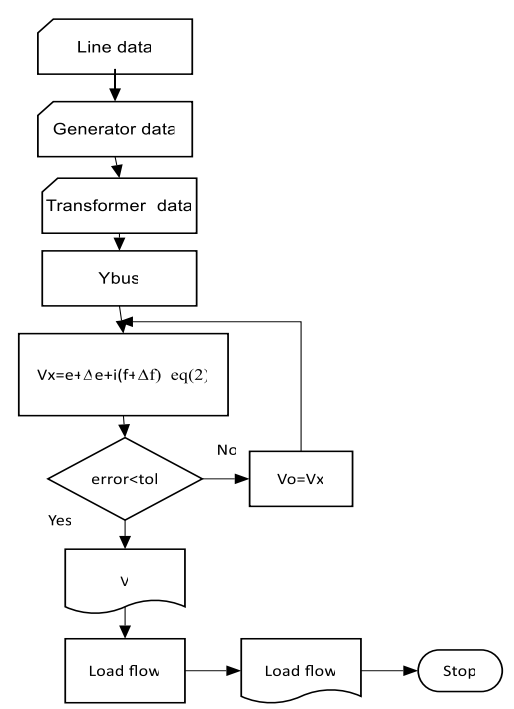

Fig. 1. Flowchart for M1 method

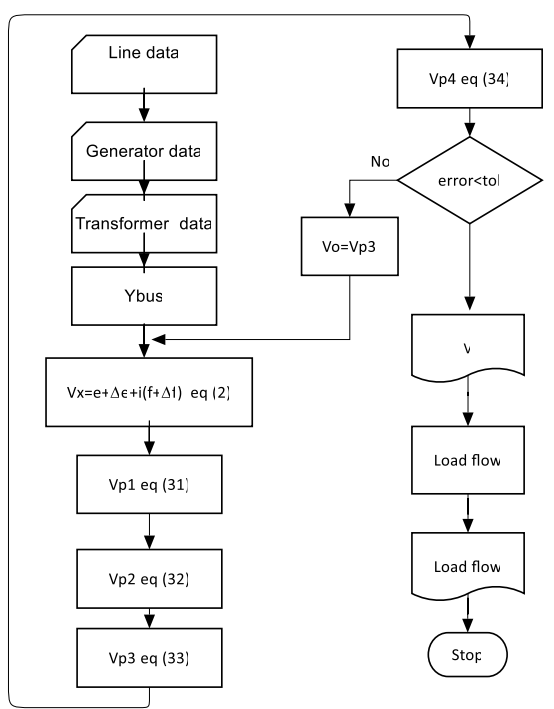

Fig. 2. Flowchart for M2 method
In each block of Figure 1, the following activities are carried out;

1. - Reading general data, such as; number of nodes, number of lines, base power, number of transformers and the slack node.

2. - Reading data of transmission lines, their impedance and shunt admittance.

3. - Reading data of generated and demanded power in each node, as well as its initial voltage and the type of node.

4. - Reading of transformer data.

5. - In block four the admittance matrix is formed.

6. - In block five the increases in real and imaginary part of the voltage are calculated and its value is corrected (eq. 2).

7. - Block six corresponds to the verification of the error allowed in the iterative process.

8. - If the tolerance is already met, the process is finished by printing voltages and if desired, the load flow is calculated.

9. - If the tolerance is not yet met, values are corrected and the iterative process is continued.

In the flowchart of fig. 2, the blocks where equations (31)(34) are solved are added to fig. 1. The iterative process ends when the relative error is less than the selected tolerance. Finally, real and reactive power flow in transmission lines and transformers is calculated. In the rectangular form, the Voltage in the node $i$, is corrected with the increments calculated in each iteration. The acceleration factors are applied to the increments of the rectangular components according to (35).

$V_{i}^{k}=e_{i}^{k}+\Delta e_{i}^{k} \propto_{e o}+i\left(f_{i}^{k}+\Delta f_{i}^{k} \propto_{f o}\right) \mathrm{i} \neq$ Slack

Where:

$\propto_{e o}$ It is the acceleration factor to the real component of the Voltage,

$\propto_{f o}$ It is the acceleration factor to the imaginary component of the Voltage

\section{A. Method M1}

A distribution system of 40 nodes is simulated and magnitude of Voltage in pu values is shown in Fig. 3 [18]. The acceleration factors used in the simulations were: 1.0 , $1.0,1.5,1.5,1.8,1.8$. For the real and imaginary components, respectively. Table I shows the values calculated for the acceleration factors mentioned and are compared with those obtained in (19).

Table I: Calculated voltages (pu)

\begin{tabular}{c|c|c|c|c}
\hline Node & $\mathrm{V}(1,1)$ & $\mathrm{V}(1.5,1.5)$ & $\mathrm{V}(1.8,1.8)$ & $\mathrm{V}(18)$ \\
\hline 1 & 1 & 1 & 1 & 1 \\
2 & 0,98892 & 0,98892 & 0,9889 & 0,988547 \\
3 & 0,98058 & 0,98058 & 0,98055 & 0,979949 \\
4 & 0,97416 & 0,97415 & 0,97412 & 0,973321 \\
5 & 0,97199 & 0,97199 & 0,97196 & 0,971156 \\
6 & 0,96992 & 0,96992 & 0,96989 & 0,969083 \\
7 & 0,98192 & 0,98192 & 0,98191 & 0,981442 \\
8 & 0,97603 & 0,97604 & 0,97603 & 0,975466
\end{tabular}




\begin{tabular}{ccccc}
9 & 0,97226 & 0,97227 & 0,97225 & 0,971642 \\
10 & 0,96944 & 0,96945 & 0,96943 & 0,968798 \\
11 & 0,96744 & 0,96744 & 0,96743 & 0,966787 \\
12 & 0,97797 & 0,97797 & 0,97795 & 0,977315 \\
13 & 0,97456 & 0,97456 & 0,97453 & 0,973894 \\
14 & 0,97186 & 0,97185 & 0,97182 & 0,971021 \\
15 & 0,96762 & 0,96762 & 0,96759 & 0,966719 \\
16 & 0,964 & 0,964 & 0,96397 & 0,963045 \\
17 & 0,96198 & 0,96199 & 0,96195 & 0,961022 \\
18 & 0,96957 & 0,96957 & 0,96954 & 0,968708 \\
19 & 0,96685 & 0,96684 & 0,96681 & 0,965953 \\
20 & 0,96455 & 0,96455 & 0,96451 & 0,963648 \\
21 & 0,98028 & 0,98029 & 0,98027 & 0,979798 \\
22 & 0,97391 & 0,97392 & 0,97391 & 0,973319 \\
23 & 0,97278 & 0,97278 & 0,97277 & 0,972177 \\
24 & 0,97083 & 0,97084 & 0,97083 & 0,970211 \\
25 & 0,96729 & 0,9673 & 0,96729 & 0,966643 \\
26 & 0,97537 & 0,97537 & 0,97534 & 0,974683 \\
27 & 0,97324 & 0,97323 & 0,97321 & 0,972542 \\
28 & 0,97043 & 0,97043 & 0,97039 & 0,969589 \\
29 & 0,96591 & 0,96591 & 0,96587 & 0,964992 \\
30 & 0,95852 & 0,95853 & 0,95849 & 0,957499 \\
31 & 0,95471 & 0,95473 & 0,95469 & 0,953644 \\
32 & 0,95297 & 0,95298 & 0,95294 & 0,951894 \\
32 & 0,96685 & 0,96685 & 0,96681 & 0,965977 \\
34 & 0,96513 & 0,96512 & 0,96508 & 0,964226 \\
35 & 0,97192 & 0,97193 & 0,97191 & 0,971318 \\
36 & 0,97366 & 0,97366 & 0,97364 & 0,972971 \\
37 & 0,95605 & 0,95607 & 0,95603 & 0,955027 \\
38 & 0,95208 & 0,9521 & 0,95205 & 0,950986 \\
39 & 0,95039 & 0,95041 & 0,95036 & 0,94929 \\
40 & 0,94989 & 0,94991 & 0,94987 & 0,948792 \\
\hline & & & & \\
\hline
\end{tabular}

In Figure 3, the values in Table I are shown graphically

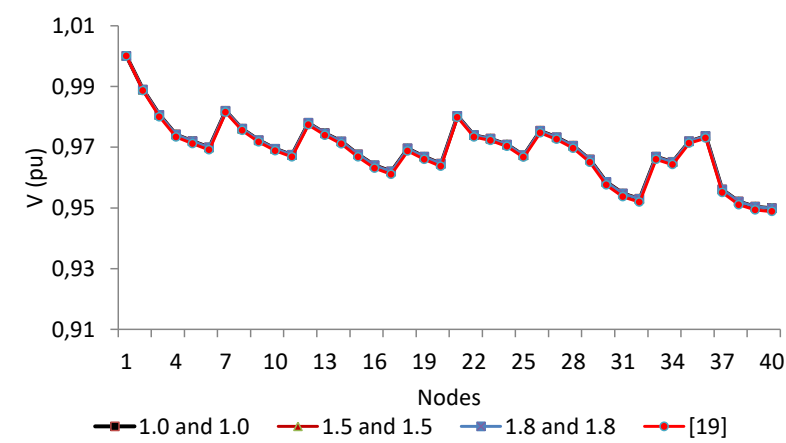

Fig. 3. Voltages for the system of 40 nodes

Fig. 4 shows the angle of the Voltages of fig. 3.

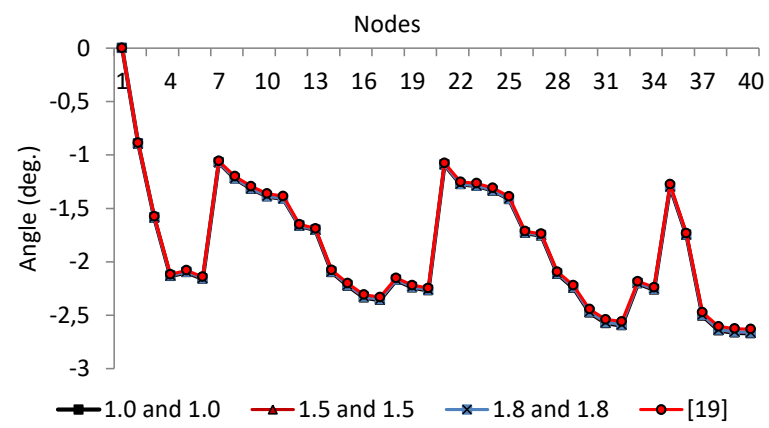

Fig. 4. Angles for the 40-node system
Fig. 5 shows iterations number and execution time in milliseconds

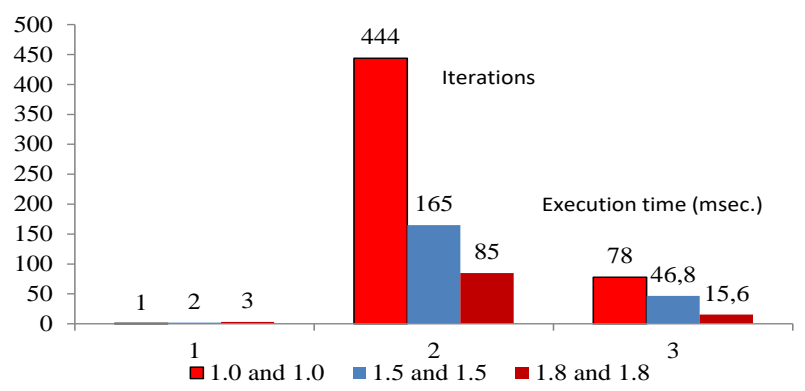

Fig. 5. Iterations and execution time for the 40 -node system

The 118-node test system of the IEEE was simulated and the magnitude of the Voltages of each node is shown in Fig. 6 when acceleration factors are; 1.0, 1.0, 1.5, 1.5 and 1.5, 1.8, in the real and imaginary components, respectively.

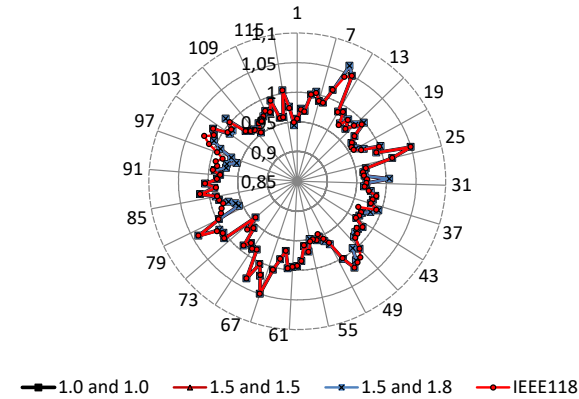

Fig. 6. Voltage magnitude for the 118 nodes system [20]

The number of iterations and execution time in milliseconds are shown in fig. 7.

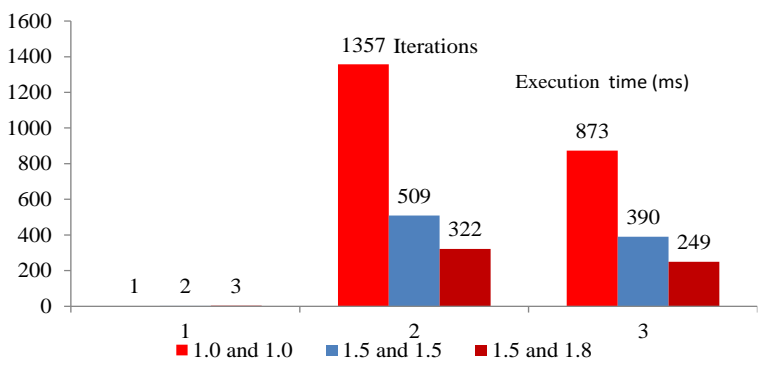

Fig. 7. Execution time and iterations number

Fig. 8 shows the relative error of the magnitude of the Voltage in the system of 40 nodes between the M1 method and [19].

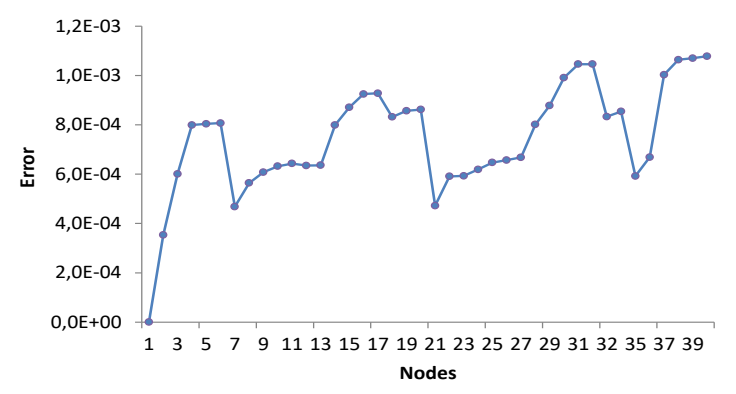

Fig. 8. Relative error in the 40 nodes system

Published By:

Blue Eyes Intelligence Engineering

DOI: 10.35940/ijeat.B2529.129219

Journal Website: www.ijeat.org 
Fig. 9 shows the relative error of the Voltage angle in the 40 node system between the M1 method and the one reported in [19]

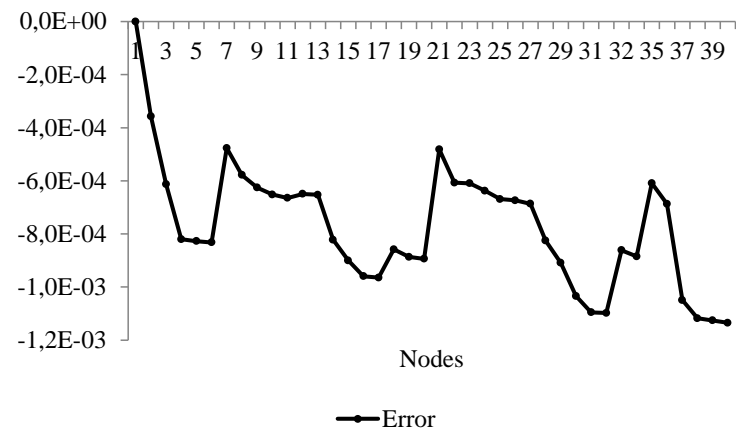

Fig. 9. Relative error between the values of M1 and the one reported in [19]

\section{B. Methods M1 and M2}

Table II shows the values of Voltages calculated with the two methods and the one reported in [18]. Table II shows the values of Voltages calculated with the two methods and the one reported in [19].

Table II: Voltages calculated with methods M1, M2 and

\begin{tabular}{|c|c|c|c|}
\hline \multicolumn{4}{|c|}{ [19] } \\
\hline Node & V pu(M1) & V pu (M2) & V pu(18) \\
\hline 1 & 1 & 1 & 1 \\
\hline 2 & 0,9889 & 0,9863 & 0,988547 \\
\hline 3 & 0,98055 & 0,9757 & 0,979949 \\
\hline 4 & 0,97412 & 0,9674 & 0,973321 \\
\hline 5 & 0,97196 & 0,9652 & 0,971156 \\
\hline 6 & 0,96989 & 0,9632 & 0,969083 \\
\hline 7 & 0,98191 & 0,9792 & 0,981442 \\
\hline 8 & 0,97603 & 0,9733 & 0,975466 \\
\hline 9 & 0,97225 & 0,9694 & 0,971642 \\
\hline 10 & 0,96943 & 0,9666 & 0,968798 \\
\hline 11 & 0,96743 & 0,9646 & 0,966787 \\
\hline 12 & 0,97795 & 0,9731 & 0,977315 \\
\hline 13 & 0,97453 & 0,9696 & 0,973894 \\
\hline 14 & 0,97182 & 0,9651 & 0,971021 \\
\hline 15 & 0,96759 & 0,9605 & 0,966719 \\
\hline 16 & 0,96397 & 0,9566 & 0,963045 \\
\hline 17 & 0,96195 & 0,9546 & 0,961022 \\
\hline 18 & 0,96954 & 0,9628 & 0,968708 \\
\hline 19 & 0,96681 & 0,9601 & 0,965953 \\
\hline 20 & 0,96451 & 0,9577 & 0,963648 \\
\hline 21 & 0,98027 & 0,9776 & 0,979798 \\
\hline 22 & 0,97391 & 0,9711 & 0,973319 \\
\hline 23 & 0,97277 & 0,97 & 0,972177 \\
\hline 24 & 0,97083 & 0,968 & 0,970211 \\
\hline 25 & 0,96729 & 0,9644 & 0,966643 \\
\hline 26 & 0,97534 & 0,9704 & 0,974683 \\
\hline 27 & 0,97321 & 0,9683 & 0,972542 \\
\hline 28 & 0,97039 & 0,9636 & 0,969589 \\
\hline 29 & 0,96587 & 0,9588 & 0,964992 \\
\hline 30 & 0,95849 & 0,9508 & 0,957499 \\
\hline 31 & 0,95469 & 0,9467 & 0,953644 \\
\hline 32 & 0,95294 & 0,945 & 0,951894 \\
\hline 32 & 0,96681 & 0,96 & 0,965977 \\
\hline 34 & 0,96508 & 0,9583 & 0,964226 \\
\hline 35 & 0,97191 & 0,9691 & 0,971318 \\
\hline 36 & 0,97364 & 0,9687 & 0,972971 \\
\hline 37 & 0,95603 & 0,9483 & 0,955027 \\
\hline 38 & 0,95205 & 0,944 & 0,950986 \\
\hline 39 & 0,95036 & 0,9423 & 0,94929 \\
\hline 40 & 0,94987 & 0,9418 & 0,948792 \\
\hline
\end{tabular}

Fig. 10 shows the magnitude of the Voltages for 40 node system when carrying out the simulation with M1, M2 methods and those obtained in [19].

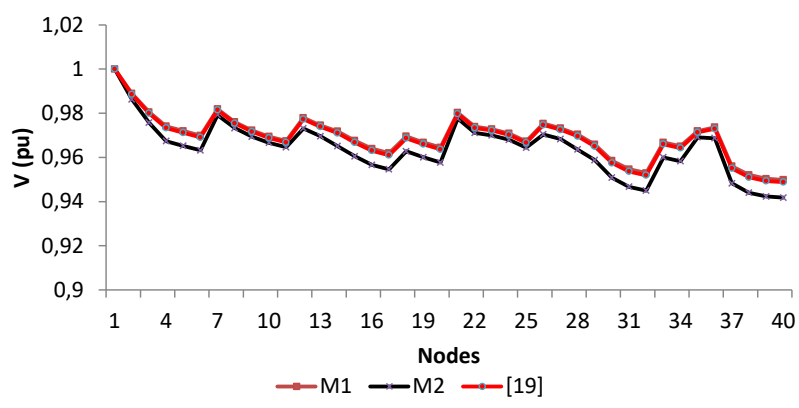

Fig. 10. Voltages obtained with M1, M2 methods and [19]

The angle of Voltages is shown in fig. 11.

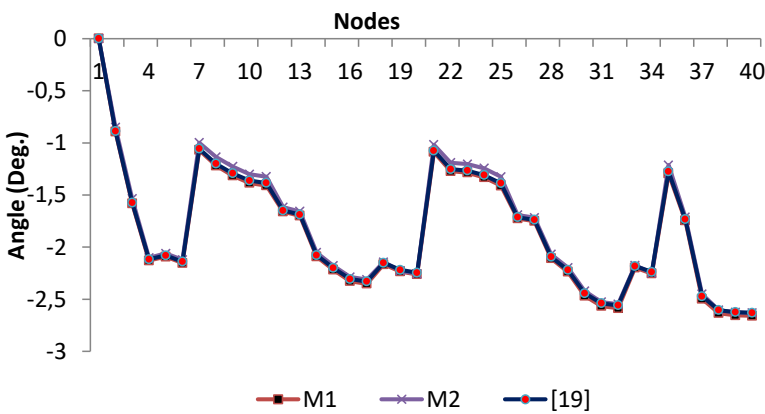

Fig. 11. Voltages Angle for the network of 40 nodes

The IEEE test system of 118 nodes was simulated with the M1, M2 methods and the magnitude of the voltages is shown in Fig. 12 and compared with those reported in [20].

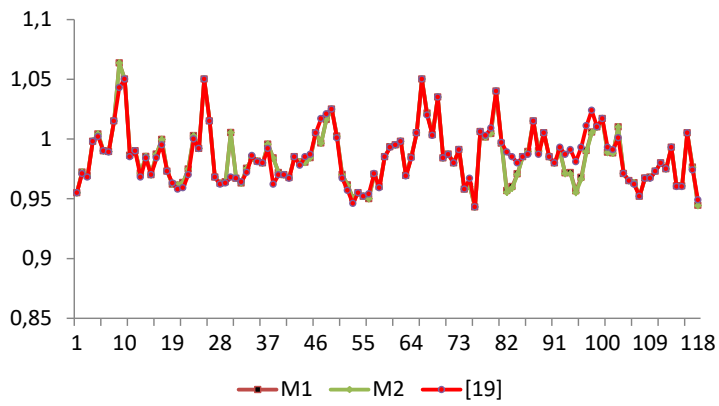

Fig. 12. Voltages for the system of 118 nodes

The execution time and the number of iterations are calculated in the simulation with the methods M1 and M2, they are shown in the bar diagram of fig. 13.

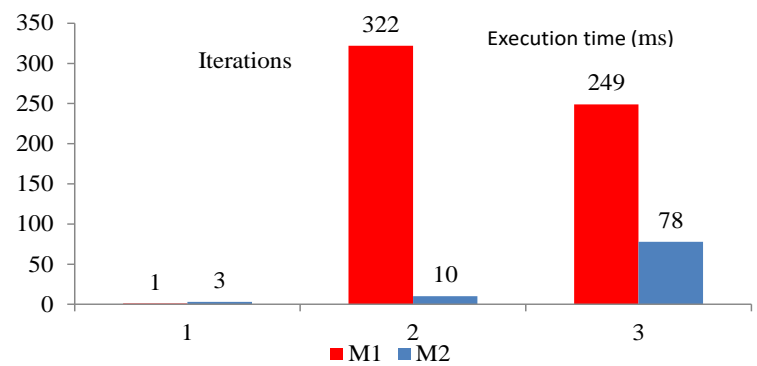

Fig. 13. Iterations and execution time for the 118 nodes system

Published By:

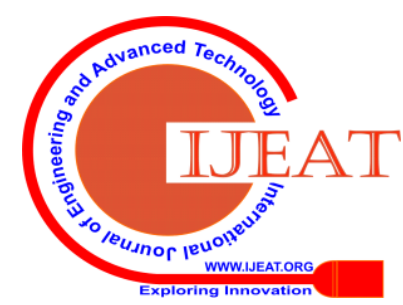


For the system of 118 nodes, the error percentage is calculated in the nodes where the difference is greater when carrying out the simulation with two methods, and is shown in fig. 14.

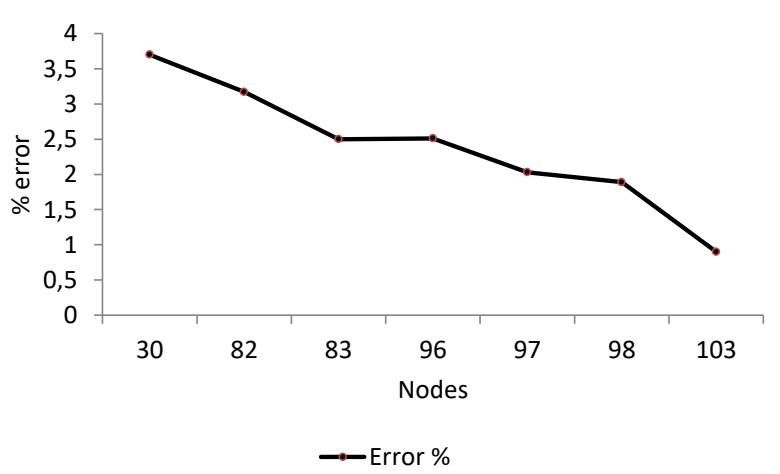

Fig. 14. Error in percent

The M1 method requires the use of acceleration factors to reduce the execution time, as can be seen in Figure 5. The number of iterations of 85 is high, however, the execution time is 15.6 milliseconds. The errors in the magnitude and angle are small, as can be seen graphically in fig. 3-4 and 89.The fact of neglecting the elements outside the main diagonal of matrices $J_{1}, J_{2}, J_{3}$ and $J_{4}$ of the original Jacobian matrix, results in an increase in the number of iterations for the systems studied (see fig. 5 and 7), however, the number of evaluations is reduced, which is ultimately what affects Run time. To reduce the number of iterations, which has always been considered as a reference, the reduced form of the rectangular version of the Newton-Raphson method has been used as a predictor method, considering the four-step method as a corrector, this in order to reduce the number of iterations and perhaps the most important; The, execution time. For the system of 118 nodes, fig. 12 graphically shows the magnitude of the Voltages and the maximum observed error is shown in fig. 14. The number of iterations and the execution time are considerably reduced, as shown in Fig. 13. Controlled Voltage nodes are treated like any other load node, calculating their reactive power and adjusting the Voltage as recommended by classical literature of electrical power systems

\section{Discussion}

Equation (1) considers that node one is the reference, however, it can be either. Neglecting the elements outside the main diagonal of (1), we have (36)

$\left[\begin{array}{ccc}\frac{\partial \mathrm{P}_{2}}{\partial \mathrm{e}_{2}} & \cdots & 0 \\ \vdots & \frac{\partial \mathrm{P}_{\mathrm{i}}}{\partial \mathrm{e}_{\mathrm{i}}} & \vdots \\ 0 & \cdots & \frac{\partial \mathrm{P}_{\mathrm{N}}}{\partial \mathrm{e}_{\mathrm{N}}}\end{array}\right]\left[\begin{array}{ccc}\frac{\partial \mathrm{P}_{2}}{\partial \mathrm{f}_{2}} & \cdots & 0 \\ \vdots & \frac{\partial \mathrm{P}_{i}}{\partial \mathrm{f}_{\mathrm{i}}} & \vdots \\ 0 & \cdots & \frac{\partial \mathrm{P}_{\mathrm{N}}}{\partial \mathrm{f}_{\mathrm{N}}}\end{array}\right]$
$\left[\begin{array}{ccc}\frac{\partial \mathrm{Q}_{2}}{\partial \mathrm{e}_{2}} & \cdots & 0 \\ \vdots & \frac{\partial \mathrm{Q}_{i}}{\partial \mathrm{e}_{i}} & \vdots \\ 0 & \cdots & \frac{\partial \mathrm{Q}_{\mathrm{N}}}{\partial \mathrm{e}_{\mathrm{N}}}\end{array}\right]\left[\begin{array}{ccc}\frac{\partial \mathrm{Q}_{2}}{\partial \mathrm{f}_{2}} & \cdots & 0 \\ \vdots & \frac{\partial \mathrm{Q}_{i}}{\partial \mathrm{f}_{\mathrm{i}}} & \vdots \\ 0 & \cdots & \frac{\partial \mathrm{Q}_{\mathrm{N}}}{\partial \mathrm{f}_{\mathrm{N}}}\end{array}\right]\left[\begin{array}{c}\Delta \mathrm{e}_{2} \\ \vdots \\ \Delta \mathrm{e}_{\mathrm{N}}\end{array}\right]\left[\begin{array}{c}\Delta \mathrm{f}_{2} \\ \vdots \\ \Delta \mathrm{f}_{\mathrm{N}}\end{array}\right]=\left[\begin{array}{c}\Delta \mathrm{P}_{2} \\ \vdots \\ \Delta \mathrm{P}_{\mathrm{N}}\end{array}\right]$
$\left[\begin{array}{c}\Delta \mathrm{Q}_{2} \\ \vdots \\ \Delta \mathrm{Q}_{\mathrm{N}}\end{array}\right]$
for; $\mathrm{i}=1, \mathrm{~N}, \mathrm{i} \neq$ Slack
Equation (36) represents the simplification used in this work and was applied for load nodes and voltage controlled nodes, considering that any node can be the reference. In the controlled Voltage nodes, reactive power is calculated and included in the iterative process like any other. This formulation eliminates the formation of the Jacobian matrix, which requires a significant amount of computational resources. The simplification used in this work has a high number of iterations, as seen in fig. 5,7 and 13. It is observed in fig. 7, the effect of the acceleration factors with which you have an execution time of 249 milliseconds. The combination of the simplification of the rectangular version and the four-step method reduces the number of iterations and the execution time for the systems considered in this work. The programs were developed in FORTRAN with the free Force-2 software and with a 6 GB RAM computer. With the iterative methods used in this work, the voltage at each node is calculated. The power flow is a consequence of the voltages and their values are not reported.

\section{CONCLUSIONS}

From the results obtained in this work, we have the following conclusions: 1) The proposed simplification requires only elementary operations, an analysis of the equations involved demonstrates this; 2) For the test systems used, the applied simplification provides acceptable results with the errors reported in the Voltage graphs; 3) The application of the hybrid method allows reducing the number of iterations and what is considered more important, the execution time, 4) With the two methods proposed, only $(N-1)$ non-linear equations are solved and one system of two equations; 5) Only the nodal admittance matrix is generated in the development of the programs. Has can be seen in Figure 10, the M1 method is more approximate than the M2 method. This may be because the acceleration factors are chosen at random and a sensitivity analysis could provide the appropriate values for each system. The authors continue to work with simple code numerical methods such as those proposed here, this in order to have simpler programming algorithms.

\section{REFERENCES}

1. Ward, J. B., and Hale, H. W., "Digital Computer Solution of Power Flow problems", AIEE Transactions on Power Apparatus and Systems, Vol PAS-75, pp. 398-404, June 1956

2. Van Ness, J. E., and Griffin, J. H., "Elimination methods for flow studies", Trans. IEEE Transactions on Power Apparatus and Systems, Vol. PAS-80, p. 299, June 1961.

3. Tinney, W. H., and Hart, C. E., "Power flow solution by Newton's method", IEEE Transactions on Power Apparatus and Systems, Vol. PAS-86, No. 11, November 1967

4. Stott, B., and Alsac, O., "Fast decoupled load flow", IEEE Transactions on Power Apparatus and Systems, Vol. PAS-93, No. 3, May 1974

5. D. Villanueva, A. Feijóo, Jose, L.Pazos, "Probabilistic load flow considering correlation between generation, loads and wind power smart grid and renewable energy", 2011, 2, 12-20 doi:10.4236/sgre.2011.21002 Published Online February 2011.

6. K. Balamurugan and Dipti Srinivasan, "Review of power flow studies on distribution network with distributed generation" IEEE PEDS 2011, Singapore, 5 - 8 December 2011.

7. T. Ramana, V. Ganesh, and S. Sivanagaraju, "Simple and fast load flow solution for electrical power distribution systems", International Journal on Electrical Engineering and Informatics - Volume 5, Number 3, September 2013.
Published By:

Blue Eyes Intelligence Engineering \& Sciences Publication 
8. Cong Zhang, Haoyong Chen, Honwing Ngan, Ping Yang, and Dong Hua, "A Mixed Interval power glow analysis under rectangular and polar coordinate system", IEEE Transactions on Power Systems, Vol. 32 No 2, March 2017

9. Mohammad Ghiasi, "A Detailed Study for Load Flow Analysis in distributed power system", International Journal of Industrial Electronics, Control and Optimization IECO, Vol. 1, No. 2, pp. 153161, June, 2018

10. ETAP software

11. Hadi Saadat, Power system analysis, third edition, PSA Publishing, 2010

12. Jizhong Zhu, Optimization of power system operation, Wiley and Sons, Inc, 2009

13. Hueso José, Eulalia Martinez, Carles Teruel, "Determination of multiple roots of nonlinear equations and Applications", doi:10.1007/s10910-014-0460-8, J Math Chem, 53:880-892, 2015

14. Alicia Cordero, Moin-ud-Din Junjua Juan R. Torregrosa, Nusrat Yasmin, and Fiza Zafar, "Efficient four-parametric with-and-withoutmemory2, iterative methods Possessing High Efficiency Indices, Mathematical Problems in Engineering Volume 2018, Article ID 8093673, ttps://doi.org/10.1155/2018/8093673

15. Isaac Fried, "The systematic formation of high-order iterative Methods", Applied \& Computational Mathematics, 2014, 3:4 http://dx.doi.org/10.4172/2168-9679.1000165

16. N. A. A. Jamaludin1,a), N. M. A. Nik Long , M. Salimi and F. Ismail, "New third order convergence iterative method for finding multiple roots of nonlinear equations", Menemui Matematik, Vol. 40, No. 2: $64-71,2018$

17. Rubén Villafuerte, Jesús Medina, Rubén A. Villafuerte S., Victorino Juárez, Manuel González, "An Iterative Method to Solve Nonlinear Equations “, Universal Journal of Electrical and Electronic Engineering 6(1): 14-22, 2019 http://www.hrpub.org DOI: 10.13189/ujeee.2019.060102

18. Adejumobi I.A., Adepoju G.A. Hamzat K. A., "Iterative Techniques for Load Flow Study: A Comparative Study for Nigerian 330kv Grid System as a Case Study", International Journal of Engineering and Advanced Technology (IJEAT) ISSN: 2249 - 8958, Volume-3, Issue1, October 2013153

19. José Izquierdo Franco, "Estudio de flujos de potencia y análisis de fallas en sistemas eléctricos de distribución Radial", Tesis de maestría, Universidad Autónoma de Nuevo León, México, 2002

20. http://www.ee.washington.edu/research/pstca/

\section{AUTHORS PROFILE}

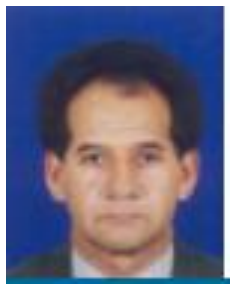

Rubén Villafuerte Díaz. He is an electrical industrial engineer, graduated from the Instituto Tecnológico de Morelia in 1979. He completed his master's and doctoral studies in the area of electrica engineering at the Instituto Politécnico Nacional, receiving the corresponding degrees in 1988 and 1993, respectively. He is currently a full-time professor at the Facultad Ingeniería of Ixtaczoquitlán, Ver., Mexico, Dependent on the Universidad Veracruzana. $\mathrm{He}$ is currently the coordinator of the Electrical Engineering Degree, his areas of interest are; the analysis of electric power systems in steady state, the calculation of electric fields, educational mathematics, electromagnetic transients and numerical methods. Email; rubenv46@yahoo.com.mx,rvillafuerte@uv.mx

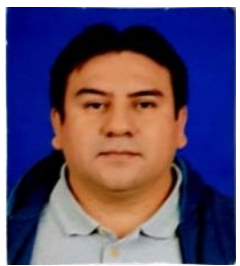

Jesús Medina Cervantes. Was born in Orizaba, Ver., México, in 1976. He received the graduate degree in Mechanical Engineering from the Instituto Tecnológico de Orizaba (ITO), Orizaba, Ver., México, in 1998, and the Master of Science degree in Mechanical Engineering from the Centro Nacional de Investigación y Desarrollo Tecnológico (CENID ET), Cuernavaca, Mor., México, in 2002. In 2001, he joined the Department of Textile Engineering, Universidad Emiliano Zapata, Cuernavaca, Mor., México, as a Professor. In 2003, he joined the Department of Design Engineering, Universidad del Papaloapan, Loma Bonita, Oaxaca., México, as a Professor. Since February 2008, he has been with the Department of Mechanical Engineering, Universidad Veracruzana, Ciudad Mendoza, Ver., México, where he is a Professor. His current research interests include Mechanical and Mechatronics Design, Automation, IoT, Robotics and Control. Email; jemedina@uv.mx

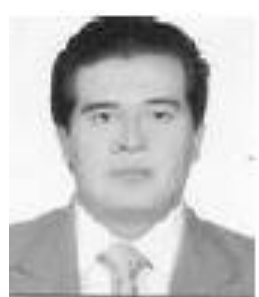

Rubén Abiud Villafuerte Salcedo. He is a mechatronic engineer, he graduated from the Popular Autonomous University of the State of Puebla in 2012. He completed his Master's studies in the area of biomedical engineering at the Popular Autonomous University of the State of Puebla in 2015. He is currently studying for a doctorate in Biomedical Engineering in the Popular Autonomous University of the State of Puebla and is a professor for hours assigned to the Faculty of Electrical Engineering at the Technological Institute of Mexico campus Orizaba, in Orizaba, Veracruz. He is a member of the institute of electrical and electronic engineers section Mexico from 2004 to date and member of the Mexican Network of biomaterials and organ and tissue engineering.

Email; dreyko999@gmail.com

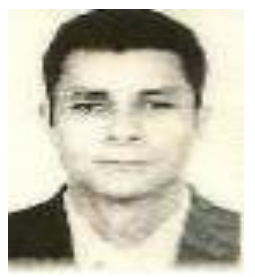

Victorino Juárez Rivera, received Eng. in Industrial Engineering in 2004 by the Instituto Tecnologico de Orizaba, his specialty line is in manufacturing, the MS degree in Mechanical Engineering in 2007 from Instituto Tecnologico de Veracruz, his research line is in materials testing he is a Full Professor in the Industrial Engineering Department, Facultad Ingenieria, Universidad Veracruzana. He is currently in charge of the Programa de Fortalecimiento a la Excelencia Educativa (PROFEXCE) Actually he is in PHD in Engineering by the Universidad Marti. His research interest includes; Six sigma, Statistical process control, Operational research and Ergonomic methods for assessing exposure to risk factor for work. Email; vijuarez@uv.mx 